\title{
Effects of hypothermia combined with neural stem cell transplantation on recovery of neurological function in rats with spinal cord injury
}

\author{
DONG WANG ${ }^{1,2}$ and JIANJUN ZHANG ${ }^{1,2}$ \\ ${ }^{1}$ Department of Neurosurgery, The Fourth Center Clinical College of Tianjin Medical University, Tianjin 300140; \\ ${ }^{2}$ Department of Neurosurgery, General Hospital of Tianjin Medical University, Tianjin 300052, P.R. China
}

Received December 7, 2013; Accepted September 18, 2014

DOI: $10.3892 / \mathrm{mmr} .2014 .2905$

\begin{abstract}
The microenvironment of the injured spinal cord is hypothesized to be involved in driving the differentiation and survival of engrafted neural stem cells (NSCs). Hypothermia is known to improve the microenvironment of the injured spinal cord in a number of ways. To investigate the effect of NSC transplantation in combination with hypothermia on the recovery of rat spinal cord injury, 60 Sprague-Dawley female rats were used to establish a spinal cord hemisection model. They were divided randomly into three groups: A, spinal cord injury group; B, NSC transplantation group; and C, NSC transplantation + hypothermia group. At 1,2,4,6 and 8 weeks post-injury, the motor function of all animals was evaluated using the Basso, Beattie and Besnaham locomotor scoring system and the inclined plane test. At 4 weeks post-transplantation, histological analysis and immunocytochemistry were performed. At 8 weeks post-transplantation, horseradish peroxidase nerve tracing and transmission electron microscopy were conducted to observe axonal regeneration. The outcome of hind limb motor function recovery in group $\mathrm{C}$ significantly surpassed that in group B at 4 weeks post-injury $(\mathrm{P}<0.05)$. Recovery was also observed in group A, but to a lesser degree. For the pathological sections no neural axonal were observed in group A. A few axon-like structures were observed in group B and more in group C. Horseradish peroxidase-labeled neurofibers and bromodeoxyuridine-positive cells were observed in the spinal cords of group C. Fewer of these cells were found in group B and fewer still in group A. The differences among the three groups were significant $(\mathrm{P}<0.05)$. Using transmission electron microscopy, newly formed nerve fibers and myelinated nerve fibers were observed in the central transverse plane in groups B
\end{abstract}

Correspondence to: Dr Dong Wang, Department of Neurosurgery, The Fourth Center Clinical College of Tianjin Medical University, No. 3 Zhongshan Road, Hebei, Tianjin 300140, P.R. China

E-mail: dewangdong@163.com

Key words: spinal cord injury, neural stem cells, transplantation, hypothermia, rat and $\mathrm{C}$, although these nerve fibers were not evident in group A. In conclusion, NSC transplantation promoted the recovery of hind limb function in rats, and combination treatment with hypothermia produced synergistic effects.

\section{Introduction}

With industrialization and the development of more advanced forms of transportation, the incidence of spinal cord injury (SCI) has increased. SCI is a significant cause of morbidity and mortality (1). Spinal cord injuries comprise damage that results in complete or partial loss of sensation and/or motor control, and can therefore have a marked effect on quality of life (2-4). Current treatment options include surgery, medicine, such as Ganglioside and Oxiracetam and physiotherapy, but no therapy is yet available to completely restore function.

Increasing evidence has shown that brain tissue-derived neural stem cells (NSCs) have the potential for self-proliferation and multilineage differentiation under certain conditions. NSCs are able to differentiate into a variety of cells within the nervous system, indicating that they may be used for the treatment of nerve injury (5). However, NSC transplantation alone is not sufficient for spinal cord repair, since the majority of the cells implanted into the spinal cord have been shown to differentiate into a phenotype that is restricted to glial lineages, and which rarely survive. The microenvironment of the injured spinal cord is hypothesized to be important in inducing the differentiation and survival of grafted NSCs $(6,7)$. In recent years, hypothermia $\left(33-35^{\circ} \mathrm{C}\right)$ has become an increasing focus of attention in research into the treatment of SCI and brain injury, due to its neuroprotective effects against secondary injury (8).

A large number of clinical studies have shown that hypothermia effectively reduces secondary brain and SCI injury, and also protects the central nervous system from injury. The beneficial effects of hypothermia include reducing oxygen consumption, decreasing free radical generation, delaying the release of damaged neurotransmitters, reducing inflammation, lowering metabolic demand and preventing the formation of cytotoxic edema. Even a temperature reduction of $1-2^{\circ} \mathrm{C}$ has been demonstrated to be protective against secondary neurological injury at the cellular level in any organ or tissue (9-13). 
In the present study, it was hypothesized that hypothermia improves the differentiation and survival of engrafted NSCs via its effects on the microenvironment of the injured spinal cord. To investigate this hypothesis, the microenvironment was modified by hypothermia, during transplantation of NSCs in a model of SCI. The aim of this study was to investigate the effect of NSC transplantation in combination with hypothermia on the recovery of SCI in rats.

\section{Materials and methods}

Experimental animals and reagents. This study was approved by the Scientific Review Committee and the Institutional Review board of Tianjin Medical University (Tianjin, China) and all experimental procedures adhered to the Helsinki Declaration. One 1-month-old Sprague Dawley (SD) rat and 60 healthy female SD rats (200-250 g) were obtained from the Chinese Academy of Medical Sciences Animal Laboratory (Beijing, China). L-Dulbecco's modified Eagle's medium (L-DMEM) was obtained from Gibco Life Technologies (Carlsbad, CA, USA). Fetal bovine serum was obtained from GE Healthcare Life Sciences (Logan, UT, USA). $0.01 \mathrm{~mol} / 1$ phosphate-buffered saline (PBS) powder ( $\mathrm{pH}$ 7.2) was obtained from Fuzhou Maxim Biotech Inc. (Fuzhou, China). Glutamate was obtained from Sigma-Aldrich (St. Louis, MO, USA). Trypsin was obtained from Gibco Life Technologies. EDTA was obtained from Tianjin Chemical Reagent No. 1 Plant (Tianjin, China). Horseradish peroxidase (HRP) was obtained from Santa Cruz Biotechnology, Inc. (Dallas, TX, USA). 5-bromo-deoxyuridine (Brdu) was obtained from Takara Biotechnology, Inc. (Dalian, China). Monoclonal mouse-anti-BrdU antibodies were obtained from Boehringer Manheim (Ingelhemin am Rhein, Germany). Horse anti-mouse IgG polyclonal antibodies conjugated to biotin were obtained from Vector Laboratories, Inc. (Burlingame, CA, USA).

The one-month-old male SD rats were used to collect BMSCs ( $n=5$ rats per group). All the rats were sacrificed via decapitation.

Rat bone marrow stem cell (BMSC) cultivation. The one-month-old SD rats (irrespective of gender) were sacrificed via decapitaton and disinfected using $75 \%$ alcohol for $\sim 10$ min. Bilateral removal of tibias and femurs was conducted under sterile conditions. Bone ends were removed, washed in L-DMEM $(1 \mathrm{ml})$ or stored in it or both, and prepared in single-cell suspension at a density of $3 \times 10^{4}$ cells $/ \mathrm{ml}$. Cells were inoculated into $100-\mathrm{ml}$ culture flasks and placed into an incubation box at $37^{\circ} \mathrm{C}$, with $5 \% \mathrm{CO}_{2}$ saturated humidity. The culture liquid was replenished $24 \mathrm{~h}$ later and thereafter renewed every three days. Nonadherent cells were removed, and adherent cells were expanded until they reached confluence and processed through sequential passages. The majority of contaminating hematopoietic stem cells were lost after the first passage, and following the second passage, cultures contained a morphologically homogenous cell population, designated BMSCs. This was confirmed by fluorescence-activated cell-sorting analysis, which demonstrated a lack of expression of typical hematopoietic cell surface markers, including CD45, CD34 and CD14, and positivity for CD71, CD105 and CD44. Mesenchymal stem cells CD44, CD90, and CD105 were positively expressed, while CD34 and CD45 were negatively expressed.Cells between passages three and six were used for subsequent experiments. They were labeled using a medium containing BrdU (Takara Biotechnology, Dalian, China).

Establishment of animal models. A total of 60 female SD rats (200-250 g) were fed standard animal feed (GB14924.2-2001) in the laboratory for 2 weeks and then anesthetized with an intraperitoneal injection of $2.5 \%$ ketamine $20 \mathrm{mg} / \mathrm{kg}$ (Hainan Kai-Pharmaceutical Co., Ltd., Hainan, China). In the prone position, rats were fixed on the operating table in order to enable preparation of skin specimens, which were then thoroughly disinfected. T9 spinous processes were identified and $2-3 \mathrm{~cm}$ of skin and subcutaneous tissue overlying this area were incised along the posterior median line. Paraspinal muscles were stripped and the T8-T9 spinous processes and lamina were exposed. Using rat forceps, T8 and T9 spinous processes and lamina were removed, exposing the dura mater. The right side of the spinal cord was then cut. Paralysis of the right hind limb was considered to indicate a successful model of SCI. Wounds were rinsed with penicillin (Hainan Kai-Pharmaceutical Co., Ltd., Hainan, China) and saline, and then sutured. Subsequently, the passage of urine was encouraged twice per day, morning and evening, by squeezing the rats' bladders, until the micturition reflex was restored.

\section{Animal grouping and mild hypothermia treatment. An HP-V26} temperature meter (Beijing Zhongxiyuanda Technology Co., Ltd., Beijing China) was used for continuous monitoring of rat rectal temperature. The 45 rats in which a model of acute SCI had been established, were randomly divided into three groups: Group A, SCI control group; group B, single BMSC transplantation group, in which rats were placed on the operating table at room temperature with rectal temperature maintained at $(37 \pm 0.5)^{\circ} \mathrm{C}$ and at $6 \mathrm{~h}$, a $1 \mathrm{ml} \mathrm{BMSC}\left(1 \times 10^{10} / \mathrm{l}\right)$ suspension was administered intravenously through the tail using a 1-ml syringe; and group C, mild hypothermia and BMSC transplantation group, in which rats were placed on an ice blanker machine (Zhuhai Heima Medical Instrument Co., Ltd.), with rectal temperature maintained at $(34 \pm 0.5)^{\circ} \mathrm{C}$, and at $6 \mathrm{~h}$, a $1 \mathrm{ml} \mathrm{BMSC}\left(1 \times 10^{10} / \mathrm{l}\right)$ suspension was administered intravenously into the tail using a 1-ml syringe. Then animals were fed in separate cages.

Functional recovery evaluation. Following treatment, two forms of test were used to assess functional recovery. Each test was observed by two independent investigators.

Basso, Beattie and Bresnahan (BBB) score. The open-field locomotion test assesses movement, weight support and coordination. It was scored using the standardized BBB locomotor scoring system (12). BBB scores range from 0 (flaccid paralysis) to 21 (normal gait). Rats were acclimated to the test environment (90 cm diameter plastic wading pool; $4 \mathrm{~cm}$ height) prior to testing. The test was performed at 1,2, 4, 6 and 8 weeks post-SCI. The mean BBB score was calculated for each group.

Inclined plate test. An inclined plate surface was covered with a 6-mm-thick rubber pad and rats were placed in a direction of body axis perpendicular to the longitudinal axis of the inclined plate. The incline angle was gradually increased and rats were required to stay in the inclined plate for at least $5 \mathrm{sec}$ 

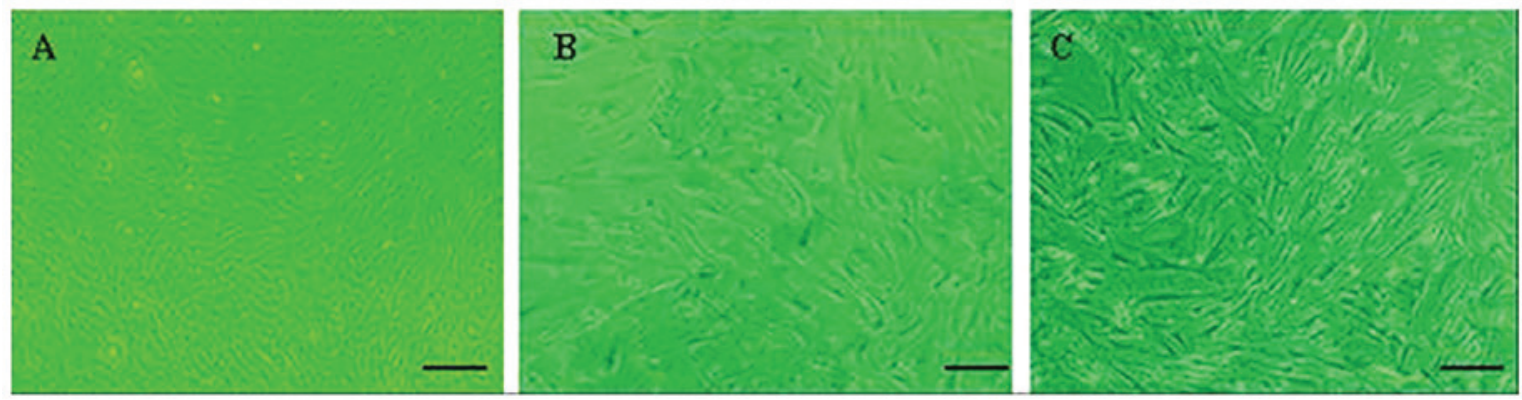

Figure 1. Morphology of neural stem cells. (A) Rat mesenchymal stem cells were cultured for 2 days. Adherent cells extended and became spindle-shaped. (B) Rat mesenchymal stem cells were cultured for 7 days and grown around a clone. (C) The 3rd passage of mesenchymal stem cells fused together and became arranged in a bunched or radiating shape. Scale bar, $50 \mu \mathrm{m}$.

to record the maximum angle achieved. The angle of incline was measured three times in each rat, and the average value was obtained. The three groups were measured at 1, 2, 4, 6 and 8 weeks post-SCI. The mean values for each group at each time point were obtained.

Histological analysis. Four weeks following SCI, two rats were randomly selected from each group for histological analysis. Dissected spinal cord tissues were post-fixed for $3 \mathrm{~h}$ in $4 \%$ paraformaldehyde, soaked overnight in $10 \%$ and then $30 \%$ sucrose, and cut into $15-\mathrm{mm}$ sagittal and parasagittal sections using a cryostat. Hematoxylin and eosin staining, and $1 \%$ cresyl violet staining were conducted for general histological examination.

Immunocytochemistry. Four weeks following SCI, two rats were randomly selected from each group for immunocytochemistry analysis using BrdU. This process required the pre-treatment of tissue sections to denature DNA. All staining was conducted on free-floating $40-\mu \mathrm{m}$ sections. A monoclonal mouse-anti-BrdU antibody (1:100 dilution) was used in combination with avidinbiotin complex and a horse-anti-IgG-antibody conjugated with biotin (1:167 dilution). Ten fields from each slice were randomly selected and viewed under a high-power microscope (x200) (Metallurgical Microscope; Shanghai Optical Instrument Production Company, Shanghai, China). The mean number of theBrdU-positive cells in each field of vision was calculated for each sample.

HRP retrograde neural tracing. Eight weeks following SCI, two rats were randomly selected from each group for HRP retrograde neural tracing. Following surgery, the spinal cord was exposed at T12 and $1 \mu \mathrm{l}$ aqueous suspension of $30 \% \mathrm{HRP}$ ( $R Z>3.0$, which represented the enzyme purity) was injected $1 \mathrm{~mm}$ bilaterally to the spinal dorsal vein. Following injection, the wound was closed and tissue samples of the animals were maintained for $36 \mathrm{~h}$ prior to being perfused by with buffer and then fixed with $1 \%$ paraformaldehyde and $1.25 \%$ glutaraldehyde. Spinal cords were removed and stored in $20 \%$ sucrose in $0.1 \mathrm{M}$ PBS at $4^{\circ} \mathrm{C}$ overnight. The spinal cord was dissected and ten fields from each slice were randomly selected in which to calculate the HRP-labeled neurofibers under a high-power microscope (x200). The mean was calculated for each group.

Electron microscopy (EM). Eight weeks following SCI, two rats from each group were randomly selected using a simple random sampling method on pre-labeled rats. They were sacrificed and perfused intracardially with saline, followed by $2 \%$ glutaraldehyde and $4 \%$ paraformaldehyde in $0.1 \mathrm{M}$ sodium cacodylate buffer ( $\mathrm{pH}$ 7.4). Immediately following perfusion, the spinal cords were removed and post-fixed in the same medium (comprising a mixture of the primary and secondary antibody) overnight at $4^{\circ} \mathrm{C}$. The spinal cord segment at the injury epicenter was sliced into $1-\mathrm{mm}$ sections, post-fixed for $2 \mathrm{~h}$ in $1 \% \mathrm{OsO}_{4}$ in $0.1 \mathrm{M}$ cacodylate buffer, dehydrated in graded ethanol solutions and embedded in Epon-812 (Hyde Venture (Beijing) Biotech Co., Ltd.). Plastic sections $(1 \mu \mathrm{m})$ were cut and stained with $1 \%$ toluidine blue prior to examination with a Nikon Eclipse TE300 microscope (Tokyo, Japan) equipped with a Spot RT Color CCD camera (Basler, Genmany). For EM, blocks were trimmed and sections were cut at $100 \mathrm{~nm}$, mounted on copper grids, stained with uranyl acetate and lead citrate, and viewed with a JEOL Jem 1200 EX transmission electron microscope (JEOL, Tokyo, Japan).

Statistical analysis. Data are expressed as the mean \pm standard deviation in this randomized control trial design. Analysis of variance was performed using SPSS 16.0 statistical software (SPSS Inc., Chicago, IL, USA). Two sample comparison was conducted using Dunnett's t-test. $\mathrm{P}<0.05$ was considered to indicate a statistically significant difference. All analyses were performed with SPSS statistical software (version 16.0).

\section{Results}

Morphology of NSCs. The number of bone marrow stromal cells and colonies were significantly increased on the fifth day of culture. Cells at passages 1-3 proliferated actively and the majority of cells adhered to the monolayer, with various morphological forms, including spindle-shaped, oval-shaped, flat-shaped, triangular and irregular cell bodies. Cells exhibited strong refraction and possessed $>2$ processes, some of which connected to each other, showing nucleus and nucleolus. When the cells were confluent, they were observed to grow in a parallel or spiral manner (Fig. 1).

$B B B$ scores. Following SCI, rats manifested full monoplegia with no activity of the right hind limb or tail, and urinary dysfunction but no dysfunction of defecation. The retraction to the puncture, including the manifestation of the movement from contraction to stretch of hind legs, began to emerge at 
Table I. BBB scores of each group at different time points following spinal cord injury.

\begin{tabular}{llllll}
\hline & \multicolumn{3}{c}{ BBB score } \\
\cline { 2 - 6 } Group & 1 week & 2 weeks & 4 weeks & 6 weeks & 8 weeks \\
\hline A & $0.54 \pm 0.15$ & $1.49 \pm 0.28$ & $4.97 \pm 0.68^{\mathrm{a}}$ & $6.39 \pm 0.59^{\mathrm{a}}$ & $7.03 \pm 0.61^{\mathrm{a}}$ \\
B & $0.53 \pm 0.12$ & $1.62 \pm 0.23$ & $5.42 \pm 0.83^{\mathrm{b}}$ & $8.68 \pm 0.52^{\mathrm{b}}$ & $9.04 \pm 0.62^{\mathrm{b}}$ \\
C & $0.54 \pm 0.11$ & $1.73 \pm 0.14$ & $6.39 \pm 0.67^{\mathrm{a}, \mathrm{b}}$ & $9.98 \pm 0.64^{\mathrm{a}, \mathrm{b}}$ & $12.62 \pm 0.73^{\mathrm{a}, \mathrm{b}}$ \\
\hline
\end{tabular}

BBB scores for each group at different time points following spinal cord injury. Three groups exhibited the same change following injury. BBB scores in groups B and C were higher than those in group A. Data are presented as the mean \pm standard deviation. At four weeks post-injury, group $\mathrm{C}$ compared with group $\mathrm{B}, \mathrm{P}<0.05$; group $\mathrm{C}$ compared with group $\mathrm{A},{ }^{\mathrm{a}} \mathrm{P}<0.01$ (Fig. $2 \mathrm{~A}$ ). $\mathrm{BBB}$, Basso, Beattie and Bresnahan locomotor scoring system.

Table II. Tilt angles of each group at different time points following spinal cord injury.

\begin{tabular}{lccccc}
\hline & \multicolumn{5}{c}{ Tilt angle $\left(^{\circ}\right)$} \\
\cline { 2 - 5 } Group & 1 week & 2 weeks & 4 weeks & 6 weeks & 8 weeks \\
\hline A & $10.8 \pm 0.5$ & $12.0 \pm 0.6$ & $15.7 \pm 0.8^{\mathrm{a}}$ & $19.6 \pm 0.8^{\mathrm{a}}$ & $22.2 \pm 0.8^{\mathrm{a}}$ \\
B & $11.2 \pm 0.7$ & $12.6 \pm 0.4$ & $20.9 \pm 0.9^{\mathrm{b}}$ & $22.1 \pm 0.9^{\mathrm{b}}$ & $25.4 \pm 0.7^{\mathrm{b}}$ \\
C & $11.3 \pm 0.6$ & $14.4 \pm 0.7$ & $25.8 \pm 1.1^{\mathrm{a}, \mathrm{b}}$ & $27.8 \pm 1.2^{\mathrm{a}, \mathrm{b}}$ & $29.7 \pm 1.0^{\mathrm{a}, \mathrm{b}}$ \\
\hline
\end{tabular}

Tilt angles of each group at different time points following spinal cord injury. Data are presented as the mean \pm standard deviation. At 4 weeks post-injury, group $\mathrm{B}$ compared with group $\mathrm{A}, \mathrm{P}<0.05$; group $\mathrm{C}$ compared with group $\mathrm{A}$. $\mathrm{P}<0.05$; and group $\mathrm{C}$ compared with group $\mathrm{B}, \mathrm{P}<0.05$. At 6 weeks post-injury, there were significant differences between groups $\mathrm{A}$ and $\mathrm{C}(\mathrm{P}<0.01)$ and between groups $\mathrm{B}$ and $\mathrm{C}(\mathrm{P}<0.05 ; \mathrm{Fig}$. 2B).
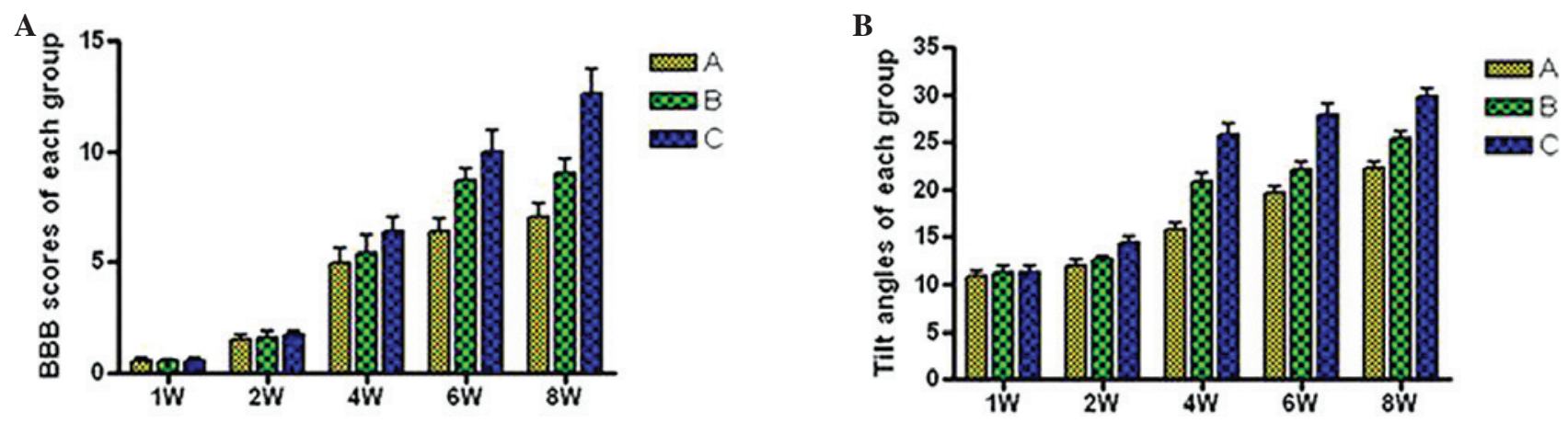

Figure 2. BBB scores and incline plate test. (A) BBB scores and (B) Tilt angles of each group at 1, 2, 4, 6 and 8 weeks following spinal cord injury. BBB, Basso, Beattie and Bresnaham locomotor scoring system. Significance levels are as shown in Tables I and II.

1 week post-injury. Hind limb movement occurred at 2 weeks post-injury and became increasingly evident at 4 weeks. Hind limbs demonstrated coordination of activities at 6 weeks and urinary function was partially restored, although there was still residual urine in the bladder. The three groups exhibited the same changes following injury. BBB scores in groups B and $\mathrm{C}$ were higher than those in group A. At 4 weeks post-injury, group $\mathrm{C}$ scores were significantly higher that those from group $\mathrm{A}(\mathrm{P}<0.01)$ and group $\mathrm{B}(\mathrm{P}<0.05$; Table I, Fig. 2A).

Incline plate test. At 4 weeks post-injury, scores from group $\mathrm{C}$ were significantly higher than those from group A $(25.8 \pm 1.1$ compared with $\left.15.7 \pm 0.8^{\circ}, \mathrm{P}<0.05\right)$ and from group $\mathrm{B}(25.8 \pm 1.1$ compared with $\left.20.9 \pm 0.9^{\circ}, \mathrm{P}<0.05\right)$. Scores from group B were also significantly higher than those from group A $(20.9 \pm 0.9$ compared with $15.7 \pm 0.8, \mathrm{P}<0.05)$. At 6 weeks post-injury, there remained significant differences between groups $\mathrm{A}$ and $\mathrm{C}(\mathrm{P}<0.01)$ and between groups $\mathrm{B}$ and $\mathrm{C}(\mathrm{P}<0.05)$. These results suggest that mild hypothermia in combination with NSC transplantation is superior to NSC transplantation alone in terms of functional motor recovery following SCI (Table II, Fig. 2B).

Histological analysis and immunocytochemistry. At 4 weeks following injury, spinal cord tissue damage, scarless healing and structural disorder were visible at the affected site in group A, with a clear cavity formation (Fig. 3A). In 

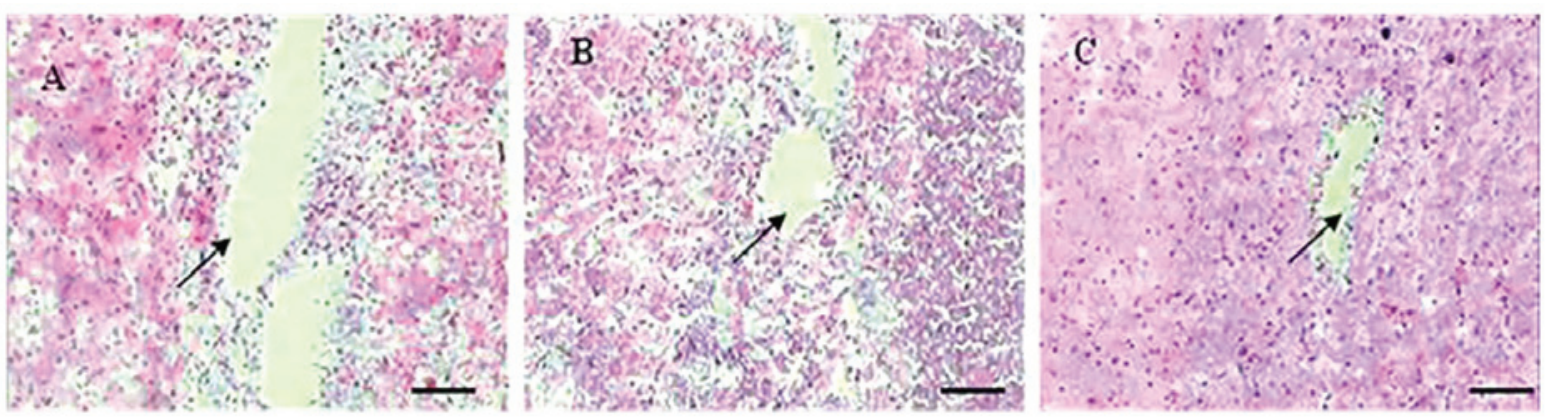

Figure 3. Histological analysis using H\&E staining. (A) Four weeks post-injury, in group A at the affected site of the damaged spinal cord exhibited a clear cavity formation. (B) In group B, astrocytes congregated at the edge of the affected site and formed scars at the junction of complete spinal cord and damaged spinal cord. The tissue cavity was smaller than that in group A but larger than that in group C. (C) In group C, astrocytes underwent a reactive hypertrophy, and congregated and formed scars at the edge of the affected site, resulting in the cavity disappearing. Arrows show Syringomyelia and scar healing. Scale bar, $100 \mu \mathrm{m}$.
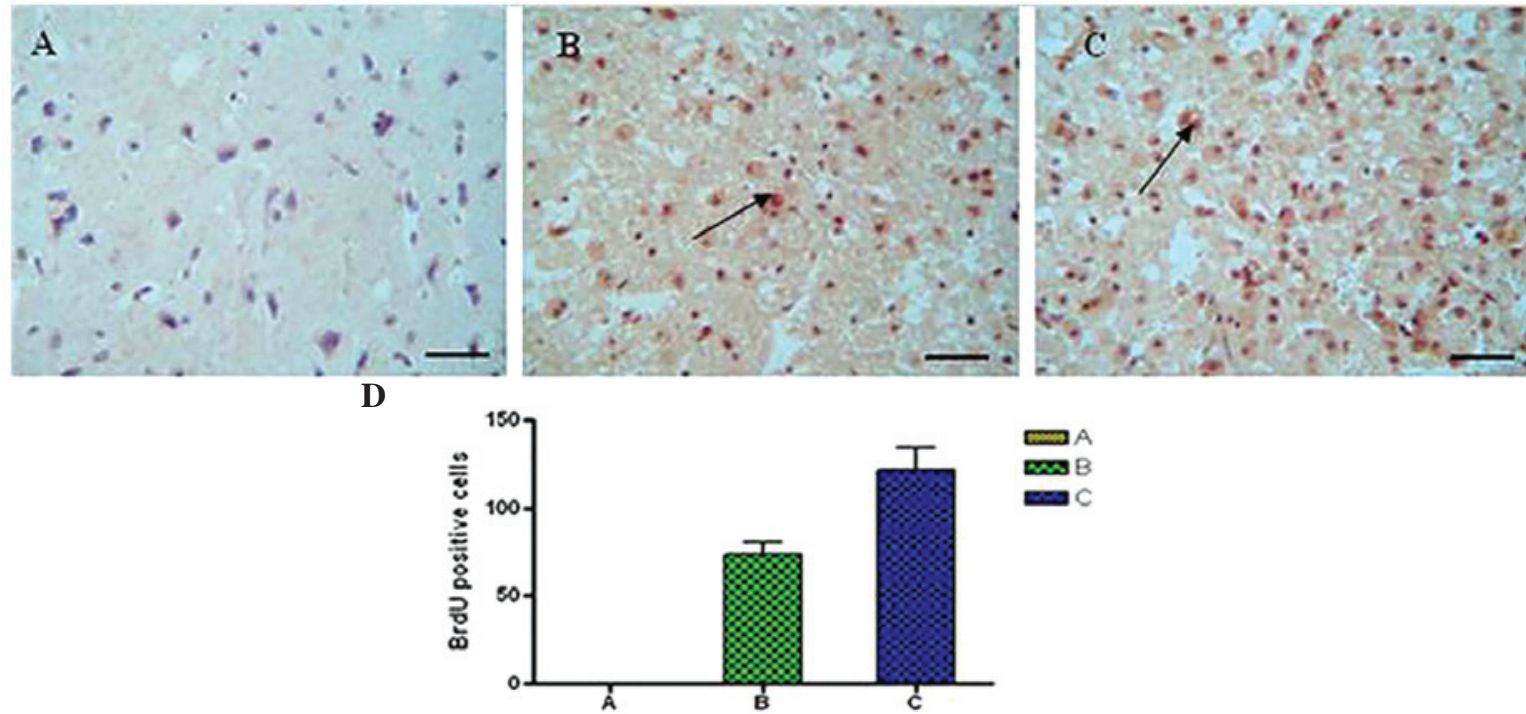

Figure 4. Immunohistochemical staining showing the number of BrdU-positive cells in the SCI lesion tissues in rats in (A) Group A, (B) group B and (C) group C. (D) Graph displaying quantity of BrdU-positive cells in each group. By analysis of variance and Dunnett's $t$-test comparison, the number of BrdU-positive cells in group $\mathrm{C}$ was found to be increased compared with group $\mathrm{B}(\mathrm{P}<0.05)$ and group $\mathrm{A}(\mathrm{P}<0.01)$. Arrows show BrdU-positive cells. Scale bar, $50 \mu \mathrm{m}$. BrDU, bromodeoxyuridine; SCI, spinal cord injury.

group B, astrocytes aggregated at the edge of the affected site and formed scars at the junction between the intact and damaged sections of the spinal cord. The cavity in group B was smaller than in group A but larger than in group C (Fig. 3B). In group C, astrocytes underwent reactive hypertrophy, aggregated and formed scars at the edge of the affected site. A number of cells were spindle-shaped, with a dense network between processes. The cavities were not visible in this group (Fig. 3C). Immunohistochemical staining showed the number of BrdU-positive cells in tissues from the SCI lesions (Fig. 4). Using analysis of variance and Dunnett's t-test, the number of BrdU-positive cells in group C (Fig. 4C) was found to be significantly increased compared with group B (Fig. 4B; $\mathrm{P}<0.05$ ), and compared with group $\mathrm{A}$ (Fig. 4A; $\mathrm{P}<0.01$ ), at 4 weeks post-injury.

$H R P$ retrograde nerve tracing. DAB color reaction was performed according to manufacturer's instructions (Shanghai ZiYi Co., Ltd.). A central area of deeply-stained tissue and a surrounding area of less strongly-stained tissue was observed at the injection site. In group A, rats were injected with HRP through the lumbar intumescentia. Two days after HRP injection, the HRP had been transported in a retrograde direction for groups $\mathrm{A}$ and $\mathrm{B}$. In segments $\mathrm{T} 8$ and above few HRP-positively labeled nerve fibers were observed (Fig. 5A). In group B, HRP-positive nerve fibers were also observed, and there were fewer fibers in group $\mathrm{C}$, although more than in group A (Fig. 5B). Group C exhibited a large quantity of HRP-positive granule-labeled nerve fibers in the spinal cord (Fig. 5C). The number of HRP-positive nerve fiber bundles in rat SCI tissues from each group is shown in Fig. 5D). There were significant differences among the three groups at 8 weeks post-injury $(\mathrm{P}<0.01)$.

Transmission electron microscopy. Transmission electron microscopy results showed the glial scar and a small number of myelinated nerve fibers in group A, along with macrophage phagocytosis and degeneration, and necrotic myelinated 

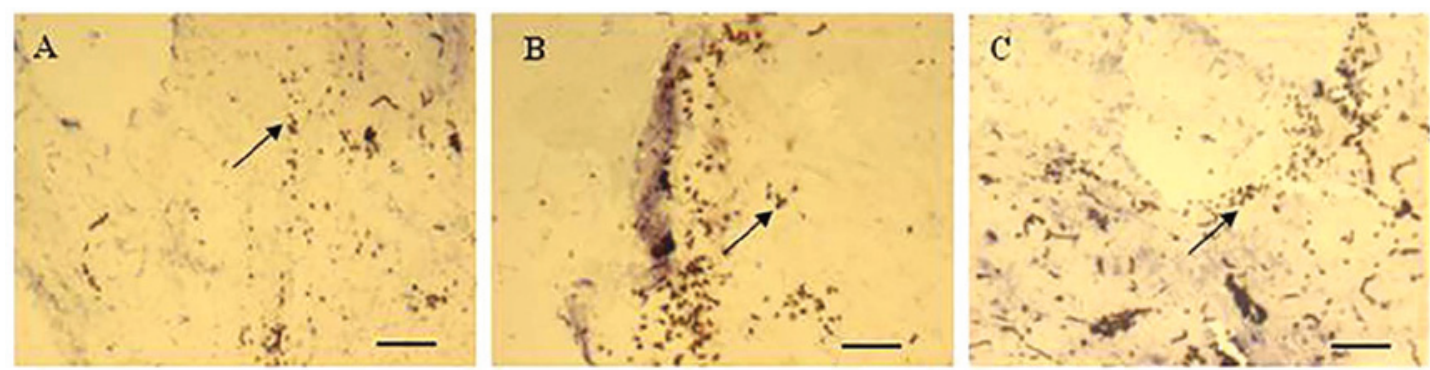

D

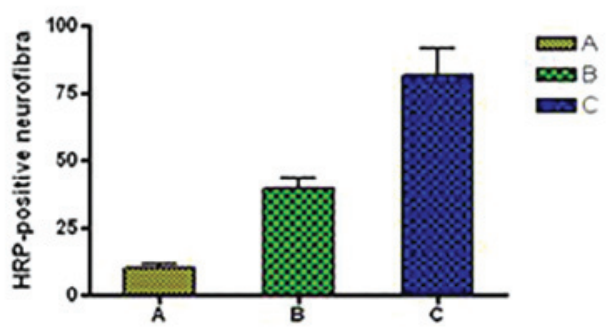

Figure 5. HRP retrograde nerve tracing. (A) In group A, few HRP-positive granule-labeled nerve fibers were observed. (B) In group B, fewer HRP-positive nerve fibers were observed than in group C, but more than group A. (C) In group C, a large quantity of HRP-positive granule-labeled nerve fibers were observed. (D) Graph displaying the number of HRP-positive cells in each group. The number of HRP-positive nerve fiber bundles in rat SCI tissues exhibited significant differences among the three groups at 8 weeks post-injury $(\mathrm{P}<0.01)$. Arrows show HRP-positive granule-labeled nerve fibers. Scale bar, $50 \mu \mathrm{m}$. HRP, horseradish peroxidase; SCI, spinal cord injury.
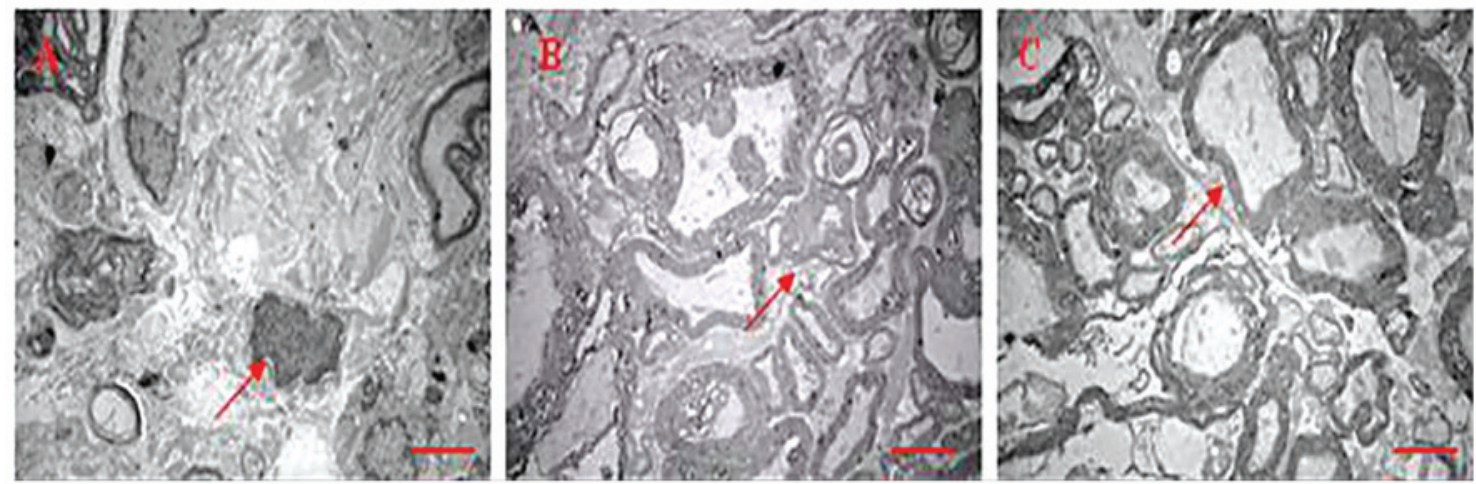

Figure 6. Transmission electron microscopy. (A) A glial scar and a small number of myelinated nerve fibers are shown in group A. (B) The number of myelinated nerve fibers and non-myelinated nerve fibers at the injury site in group B was greater than that in group A but less than that in group C. (C) Numerous myelinated and non-myelinated nerve fibers were observed in group $\mathrm{C}$, with more axons and intact myelin. Arrows show a glial scar and a small number of myelinated nerve fibers. Scale bar, $0.1 \mu \mathrm{m}$.

nerve fibers (Fig. 6A). A large number of myelinated and non-myelinated nerve fibers were observed in group $\mathrm{C}$, which had more axons and intact myelin as compared with the other groups (Fig. 6B). The number of myelinated and non-myelinated nerve fibers at the injury site in group $\mathrm{B}$ was greater than that in group A and less than that in group C (Fig. 6C).

\section{Discussion}

Central nervous system regeneration is a complex area of theoretical research and clinical practice in the fields of neuroscience and medicine, and an effective treatment for damage to the nervous system has not yet been developed. Central nervous system injury is primarily a result of trauma, including cerebral cortex impairment or loss of function and paralysis as a result of SCI (14-16). Recently, with the development of stem cell research, NSC transplantation for the treatment of neurological diseases has become a significant focus in medical research (17-19). NSCs have a number of superior qualities as compared to neurons, such as ease of harvesting, well-developed methods for cell separation, culture, amplification and exogenous gene transfection, and the feasibility of autologous implantation following in vitro amplification or genetic engineering modification, without encountering ethical issues or immune rejection. NSC transplantation has been shown to effectively treat nervous system injury in a previous study (20). Its mechanisms of action are diverse. NSCs exhibit a high expansion potential, genetic stability and a stable phenotype. They are easily collected and transported, and are compatible with different delivery methods and formulations (21). In addition, NSCs have two other important characteristics: They are able to migrate to sites of tissue injury and they have strong immunosuppressive properties that can be exploited for successful autologous or 
heterologous transplantation without the requirement for pharmacological immunosuppression $(22,23)$. NSCs are capable of differentiating into neurons and astrocytes in vitro and in vivo (24). Recently, NSC injection has shown promising results in the treatment of amyotrophic lateral sclerosis in humans (25). They have been shown to improve neurological deficits and promote the development of neuronal networks with functional synaptic transmission, when transplanted into animal models of neurological disorders, such as nerve dysfunction (26). NSCs have been observed to migrate to injured tissues and to mediate functional recovery following brain, spinal cord and peripheral nerve lesions (27).

In recent years, mild hypothermia $\left(33-35^{\circ} \mathrm{C}\right)$ has received increasing attention in the treatment of central nervous system injury. A previous clinical study showed that mild hypothermia effectively reduces secondary nerve injury and protects against severe traumatic brain injury (28). The mechanisms underlying this protective effect may include reducing the release of excitatory amino acids, inhibiting calcium influx, regulating calmodulin kinase II and protein kinase $\mathrm{C}$ activity, inhibiting the inflammatory response following cerebral ischemia, suppressing edema formation, reducing the oxygen metabolic rate, diminishing the production of free radicals, and inhibiting necrosis and neuronal apoptosis induced by mitochondrial release of cytochrome $c$ (29-31). In the present study, the effect of mild hypothermia combined with NSC transplantation on SCI in rats was investigated. The results showed that NSC transplantation combined with mild hypothermia was superior to NSC transplantation alone, in the treatment of SCI in rats, as evaluated by changes in histology and functional recovery.

The synergistic effect of hypothermia and NSC transplantation may be due to the fact that hypothermia improves the microenvironment of the injured spinal cord. An important mechanism underlying the neuroprotective effects of hypothermia is a reduction or delay in metabolic consumption during the period of stress experienced by the injured spinal cord (32-36). The hemodynamic consequences of cooling the spinal cord are important, as reductions in blood flow to critical levels caused by profound cooling may have adverse effects on tissue preservation and thus on functional outcome (37-39). It is clear that the neurotransmitter response in various types of SCI models may be temperature-dependent, but that attenuating other injury cascade may be more important in subserving the beneficial effects of hypothermia (40-43). Alterations in blood-brain barrier permeability following ischemia and trauma are an important vascular consequence that leads to the passage of water, blood-borne exogenous substances and potential neurotoxic agents across the vascular system and into the brain parenchyma. Microvascular perturbations including blood-brain barrier permeability, the formation of vasogenic edema and the extravasation of circulating inflammatory cells may adversely affect injury outcome. The effects of hypothermia on the vasculature comprise an important mechanism contributing to the beneficial effects of hypothermia (44-47). There are also pronounced changes in calcium-dependent intracellular signaling pathways following SCI. The neuronal cytoskeleton is highly vulnerable to injury, resulting in beading of dendrites and degeneration of axons, changes that are reversed by hypothermia. This effect is likely to be mediated by the inhibition of calpain activity, a calcium-dependent protease (48-52). Attenuation of inflammation is one of the major mechanisms by which hypothermia leads to beneficial effects in SCI. The inflammatory response following SCI is known to be significantly attenuated by hypothermia. In addition to attenuating the disruption of the blood-brain barrier and the extravasation of infiltrating inflammatory cells and neurotoxic substances, the endogenous inflammatory response induced by SCI is also reduced by hypothermia (53-55). Evidence for apoptotic cell death has been demonstrated in various models of SCI. Although neuronal necrosis is commonly observed in injury models, evidence for apoptotic cell death in CNS injury has also been documented using various histochemical and molecular techniques. As with necrosis, apoptotic cell death appears to be sensitive to post-injury hypothermic treatment strategies. Using terminal deoxynucleotidetransferase-mediated dUTP-biotin nick end labeling staining, DNA fragmentation has been found to be reduced by hypothermia in SCI (56-59). Recent studies have utilized various genetic markers in order to evaluate the effects of temperature on molecular events associated with SCI. Families of genes associated with inflammation, apoptosis and other cell signaling cascades are known to be reduced or elevated when brain temperature is lowered. The ability of post-injury temperature to affect the acute and delayed genetic responses to injury is important, as these genes may be important in determining the proteomic response that results in secondary injury (60-63).

In conclusion, NSC transplantation in combination with mild hypothermia may promote the survival, proliferation, differentiation and migration of the transplanted cells at the injury site, as well as promoting the restoration of nerve function in rats with SCI. This therapy provides novel strategies and methods for the clinical treatment of SCI.

\section{Acknowledgements}

This study was sponsored by the Application Basis and Front Technology Projects of Tianjin (Science and Technology Foundation of Tianjin, No. 12JCYBJC18000.

\section{References}

1. Ku JH: The management of neurogenic bladder and quality of life in spinal cord injury. BJU Int 98: 739-745, 2006.

2. Papadopoulos SM, Selden NR, Quint DJ, Patel N, Gillespie B and Grube S: Immediate spinal cord decompression for cervical spinal cord injury: feasibility and outcome. J Trauma 52: 323-332, 2002.

3. Harrop JS, Sharan AD, Vaccaro AR and Przybylski GJ: The cause of neurologic deterioration after acute cervical spinal cord injury. Spine (Phila Pa 1976) 26: 340-346, 2001.

4. Beck KD, Nguyen HX, Galvan MD, Salazar DL, Woodruff TM and Anderson AJ: Quantitative analysis of cellular inflammation after traumatic spinal cord injury: evidence for a multiphasic inflammatory response in the acute to chronic environment. Brain 133: 433-447, 2010.

5. Furuya T, Hashimoto M, Koda M, Okawa A, Murata A, Takahashi K, Yamashita T and Yamazaki M: Treatment of rat spinal cord injury with a Rho-kinase inhibitor and bone marrow stromal cell transplantation. Brain Res 1295: 192-202, 2009.

6. Ohta M, Suzuki Y, Noda T, Ejiri Y, Dezawa M, Kataoka K, Chou H, Ishikawa N, Matsumoto N, Iwashita Y, Mizuta E, Kuno $\mathrm{S}$ and Ide C: Bone marrow stromal cells infused into the cerebrospinal fluid promote functional recovery of the injured rat spinal cord with reduced cavity formation. Exp Neurol 187: 266-278, 2004. 
7. Gu Y, Wang J, Ding F, Hu N, Wang Y and Gu X: Neurotrophic actions of bone marrow stromal cells on primary culture of dorsal root ganglion tissues and neurons. J Mol Neurosci 40: 332-341, 2010

8. Nguyen HP, Zaroff JG, Bayman EO, et al: Perioperative hypothermia ( 33 degrees $C$ ) does not increase the occurrence of cardiovascular events in patients undergoing cerebral aneurysm surgery: findings from the Intraoperative Hypothermia for Aneurysm Surgery Trial. Anesthesiology 113: 327-342, 2010

9. Kobbe P, Lichte P, Wellmann M, Hildebrand F, Nast-Kolb D, Waydhas $C$ and Oberbeck R: Impact of hypothermia on the severely injured patient. Unfallchirurg 112: 1055-1061, 2009 (In German)

10. Huang T, Solano J, He D, Loutfi M, Dietrich WD and Kuluz JW: Traumatic injury activates MAP kinases in astrocytes: mechanisms of hypothermia and hyperthermia. J Neurotrauma 26 $1535-1545,2009$.

11. Dimar Jr II, Shields CB, Zhang YP, Burke DA, Raque GH and Glassman SD: The role of directly applied hypothermia in spinal cord injury. Spine (Phila Pa 1976) 25: 2294-2302, 2000.

12. Kwon BK, Mann C, Sohn HM, Hilibrand AS, Phillips FM, Wang JC and Fehlings MG; NASS Section on Biologics: Hypothermia for spinal cord injury. Spine J 8: 859-874, 2008.

13. Dietrich WD, Atkins CM and Bramlett HM: Protection in animal models of brain and spinal cord injury with mild to moderate hypothermia. J Neurotrauma 26: 301-312, 2009.

14. Cao QL, Howard RM, Dennison JB and Whittemore SR: Differentiation of engrafted neuronal-restricted precursor cells is inhibited in the traumatically injured spinal cord. Exp Neurol 177: 349-359, 2002.

15. Carvalho KA, Vialle EN, Moreira GH, Cunha RC, Simeoni RB, Francisco JC, Guarita-Souza LC, Oliveira L, Zocche L and Olandoski M: Functional outcome of bone marrow stem cells $(\mathrm{CD} 45(+) / \mathrm{CD} 34(-))$ after cell therapy in chronic spinal cord injury in Wistar rats. Transplant Proc 40: 845-846, 2008

16. Sun Z, Wen Y, Mao Q, Hu L, Li H, Sun Z and Wang D: Adenosine-triphosphate promoting repair of spinal cord injury by activating mammalian target of rapamycin/signal transducers and activators of transcription 3 signal pathway in rats Zhongguo Xiu Fu Chong Jian Wai Ke Za Zhi 24: 165-171, 2010 (In Chinese).

17. Bhang SH,Lee YE, ChoSW,Shim JW,Lee SH,ChoiCY,Chang JW and Kim BS: Basic fibroblast grow th factor promotes bone marrow stromal cell transplantation-mediated neural regeneration in traumatic brain injury. Biochem Biophys Res Commun 359: 40-45, 2007.

18. Theus MH, Wei L, Cui L, Francis K, Hu X, Keogh C and Yu SP. In vitro hypoxic preconditioning of embryonic stem cells as a strategy of promoting cell survival and functional benefits after transplantation into the ischemic rat brain. Exp Neurol 210: 656-670, 2008

19. Hwang DH, Shin HY, Kwon MJ, Choi JY, Ryu BY and Kim BG: Survival of neural stem cell grafts in the lesioned spinal cord is enhanced by a combination of treadmill locomotor training via insulin-like growth factor-1 signaling. J Neurosci 34: 12788-12800, 2014

20. Shen LH, Li Y, Gao Q, Savant-Bhonsale S and Chopp M: Down-regulation of neurocan expression in reactive astrocytes promotes axonal regeneration and facilitates the neurorestorative effects of bone marrow stromal cells in the ischemic rat brain. Glia 56: 1747-1754, 2008.

21. Giordano A, Galderisi U and Marino IR: From the laboratory bench to the patient's bedside: an update on clinical trials with mesenchymal stem cells. J Cell Physiol 211: 27-35, 2007.

22. Le Blanc K and Pittenger M: Mesenchymal stem cells: progress toward promise. Cytotherapy 7: 36-45, 2005

23. Beggs KJ, Lyubimov A, Borneman JN, Bartholomew A, Moseley A, Dodds R, Archambault MP, Smith AK and McIntosh KR: Immunologic consequences of multiple, high-dose administration of allogeneic mesenchymal stem cells to baboons. Cell Transplant 15: 711-721, 2006.

24. Jori FP, Napolitano MA, Melone MA, Cipollaro M, Cascino A, Altucci L, Peluso G, Giordano A and Galderisi U: Molecular pathways involved in neural in vitro differentiation of marrow stromal stem cells. J Cell Biochem 94: 645-655, 2005.

25. Mazzini L, Mareschi K, Ferrero I, Vassallo E, Oliveri G, Nasuelli N, Oggioni GD, Testa L and Fagioli F: Stem cell treatment in Amyotrophic Lateral Sclerosis. J Neurol Sci 265: $78-83,2008$
26. Bae JS, Han HS, Youn DH, Carter JE, Modo M, Schuchman EH and Jin HK: Bone marrow-derived mesenchymal stem cells promote neuronal networks with functional synaptic transmission after transplantation into mice with neurodegeneration. Stem Cells 25: 1307-1316, 2007.

27. Chen G, Hu YR, Wan H, Xia L, Li JH, Yang F, Qu X, Wang SG and Wang ZC. Functional recovery following traumatic spinal cord injury mediated by a unique polymer scaffold seeded with neural stem cells and Schwann cells. Chin Med J (Engl) 123: 2424-2431, 2010.

28. Li XH, Chen Z, Zhao Xia, Liang HQ, Zhao ML, Zhang S and Tu Y. Hypothermia in rats after traumatic brain injury within the endogenous neural stem cell proliferation and differentiation and its mechanism. Zhonghua Chuang Shang Za Zhi 30: 500-503, 2014.

29. Lyden PD, Krieger D, Yenari M and Dietrich WD: Therapeutic hypothermia for acute stroke. Int J Stroke 1: 9-19, 2006.

30. Deng H, Han HS, Cheng D, Sun GH and Yenari MA: Mild hypothermia inhibits inflammation after experimental stroke and brain inflammation. Stroke 34: 2495-2501, 2003.

31. Schwab S, Georgiadis D, Berrouschot J, Schellinger PD, Graffagnino C and Mayer SA: Feasibility and safety of moderate hypothermia after massive hemispheric infarction. Stroke 32: 2033-2035, 2001

32. Tohyama Y, Sako K and Yonemasu Y: Hypothermia attenuates hyperglycolysis in the periphery of ischemic core in rat brain. Exp Brain Res 122: 333-338, 1998.

33. Kaibara T, Sutherland GR, Colbourne F and Tyson RL: Hypothermia: depression of tricarboxylic acid cycle flux and evidence for pentose phosphate shunt upregulation. J Neurosurg 90: 339-347, 1999.

34. Lo EH and Steinberg GK: Effects of hypothermia on evoked potentials, magnetic resonance imaging, and blood flow in focal ischemia in rabbits. Stroke 23: 889-893, 1992

35. Sutton LN, Clark BJ, Norwood CR, Woodford EJ and Welsh FA: Global cerebral ischemia in piglets under conditions of mild and deep hypothermia. Stroke 22: 1567-1573, 1991.

36. Jiang JY, Liang YM, Luo QZ and Zhu C: Effect of mild hypothermia on brain dialysate lactate after fluid percussion brain injury in rodents. Neurosurgery 54: 713-718, 2004.

37. Rosomoff HL and Holaday DA: Cerebral blood flow and cerebral oxygen consumption during hypothermia. Am J Physiol 179: 85-88, 1954.

38. Kuluz JW, Prado R, Chang J, Ginsberg MD, Schleien CL and Busto R: Selective brain cooling increases cortical cerebral blood flow in rats. Am J Physiol 265: H824-H827, 1993.

39. Hansebout RR, Lamont RN and Kamath MV: The effects of local cooling on canine spinal cord blood flow. Can J Neurol Sci 12: 83-87, 1985

40. Baker AJ, Zornow MH, Grafe MR, Scheller MS, Skilling SR, Smullin DH and Larson AA: Hypothermia prevents ischemia-induced increases in hippocampal glycine concentrations in rabbits. Stroke 22: 666-673, 1991.

41. Rokkas CK, Cronin CS, Nitta T, Helfrich LR Jr, Lobner DC, Choi DW and Kouchoukos NT: Profound systemic hypothermia inhibits the release of neurotransmitter amino acids in spinal cord ischemia. J Thorac Cardiovasc Surg 110: 27-35, 1995.

42. Zausinger S, Westermaier T, Plesnila N, Steiger HJ and Schmid-Elsaesser R: Neuroprotection in transient focal cerebral ischemia by combination drug therapy and mild hypothermia: comparison with customary therapeutic regimen. Stroke 34: 1526-1532, 2003

43. Zhu H, Meloni BP, Bojarski C, Knuckey MW and Knuckey NW: Post-ischemic modest hypothermia (35 degrees C) combined with intravenous magnesium is more effective at reducing CA1 neuronal death than either treatment used alone following global cerebral ischemia in rats. Exp Neurol 193: 361-368, 2005.

44. Dietrich WD, Busto R, Halley M and Valdes I: The importance of brain temperature in alterations of the blood brain barrier following cerebral ischemia. J Neuropathol Exp Neurol 49: 486-497, 1990

45. Huang ZG, Xue D, Preston E, Karbalai H and Buchan AM: Biphasic opening of the blood-brain barrier following transient focal ischemia: effects of hypothermia. Can J Neurol Sci 26: 298-304, 1999

46. Arican N, Kaya M, Yorulmaz C, Kalayci R, Ince H, Kucuk M, Fincanci SK and Elmas I: Effect of hypothermia on blood-brain barrier permeability following traumatic brain injury in chronically ethanol-treated rats. Int J Neurosci 116: 1249-1261, 2006. 
47. Nagel S, Su Y, Horstmann S, Heiland S, Gardner H, Koziol J, Martinez-Torres FJ and Wagner S: Minocycline and hypothermia for reperfusion injury after focal cerebral ischemia in the rat: effects on BBB breakdown and MMP expression in the acute and subacute phase. Brain Res 1188: 198-206, 2008.

48. Hu BR, Kamme F and Wieloch T: Alterations of $\mathrm{Ca}^{2+} /$ calmodulin-dependent protein kinase II and its messenger RNA in the rat hippocampus following normo- and hypothermic ischemia. Neuroscience 68: 1003-1016, 1995.

49. Churn SB, Taft WC, Billingsley MS, Blair RE and DeLorenzo RJ: Temperature modulation of ischemic neuronal death and inhibition of calcium/calmodulin-dependent protein kinase II in gerbils. Stroke 21: 1715-1721, 1990.

50. Shimohata T, Zhao H and Steinberg GK: Epsilon PKC may contribute to the protective effect of hypothermia in a rat focal cerebral ischemia model. Stroke 38: 375-380, 2007.

51. Atkins CM, Oliva AA Jr, Alonso OF, Chen S, Bramlett HM, Hu BR and Dietrich WD: Hypothermia treatment potentiates ERK1/2 activation after traumatic brain injury. Eur J Neurosci 26: 810-819, 2007.

52. Shimohata T, Zhao H, Sung JH, Sun G, Mochly-Rosen D and Steinberg GK: Suppression of deltaPKC activation after focal cerebral ischemia contributes to the protective effect of hypothermia. J Cereb Blood Flow Metab 27: 1463-1475, 2007.

53. Ha KY and Kim YH: Neuroprotective effect of moderate epidural hypothermia after spinal cord injury in rats. Spine (Phila Pa 1976) 33: 2059-2065, 2008.

54. Morino T, Ogata T, Takeba J and Yamamoto H: Microglia inhibition is a target of mild hypothermic treatment after the spinal cord injury. Spinal Cord 46: 425-431, 2008

55. Fukui O, Kinugasa Y, Fukuda A, Fukuda H, Tskitishvili E, Hayashi S, Song M, Kanagawa T, Hosono T, Shimoya K and Murata Y: Post-ischemic hypothermia reduced IL-18 expression and suppressed microglial activation in the immature brain. Brain Res 1121: 35-45, 2006.
56. Brodhun M, Fritz H, Walter B, Antonow-Schlorke I, Reinhart K, Zwiener U, Bauer R and Patt S: Immunomorphological sequelae of severe brain injury induced by fluid-percussion in juvenile pigs - effects of mild hypothermia. Acta Neuropathol 101: 424-434, 2001.

57. Zhao H, Yenari MA, Sapolsky RM and Steinberg GK: Mild postischemic hypothermia prolongs the time window for gene therapy by inhibiting cytochrome C release. Stroke 35: 572-577, 2004.

58. Zhao H, Yenari MA, Cheng D, Sapolsky RM and Steinberg GK: Biphasic cytochrome c release after transient global ischemia and its inhibition by hypothermia. J Cereb Blood Flow Metab 25: 1119-1129, 2005

59. Zhao H, Wang JQ, Shimohata T, Sun G, Yenari MA, Sapolsky RM and Steinberg GK: Conditions of protection by hypothermia and effects on apoptotic pathways in a rat model of permanent middle cerebral artery occlusion. J Neurosurg 107: 636-641, 2007.

60. Shibuya S, Miyamoto O, Janjua NA, Itano T, Mori S and Norimatsu H: Post-traumatic moderate systemic hypothermia reduces TUNEL positive cells following spinal cord injury in rat. Spinal Cord 42: 29-34, 2004

61. Ohta H, Terao Y, Shintani Y and Kiyota Y: Therapeutic time window of post-ischemic mild hypothermia and the gene expression associated with the neuroprotection in rat focal cerebral ischemia. Neurosci Res 57: 424-433, 2007.

62. Gressens P, Dingley J, Plaisant F, Porter H, Schwendimann L, Verney C, Tooley J and Thoresen M: Analysis of neuronal, glial, endothelial, axonal and apoptotic markers following moderate therapeutic hypothermia and anesthesia in the developing piglet brain. Brain Pathol 18: 10-20, 2008.

63. Kobayashi MS, Asai S, Ishikawa K, Nishida Y, Nagata T and Takahashi Y: Global profiling of influence of intra-ischemic brain temperature on gene expression in rat brain. Brain Res Rev 58: 171-191, 2008. 